Article

\title{
Performance of GLASS and MODIS Satellite Albedo Products in Diagnosing Albedo Variations during Different Time Scales and Special Weather Conditions in the Tibetan Plateau
}

\author{
Yingying An ${ }^{1,2,3}$, Xianhong Meng ${ }^{1,2}, * \mathbb{D}$, Lin Zhao ${ }^{1,2}$, Zhaoguo $\mathrm{Li}^{1,2}$, Shaoying Wang ${ }^{1,2}$, \\ Lunyu Shang ${ }^{1,2}$, Hao Chen ${ }^{1,2}{ }^{-}$, Shihua Lyu ${ }^{4,5}$, Guangwei $\mathrm{Li}^{1,2,3}$ and Yingsai Ma ${ }^{1,2,3}$ \\ 1 Key Laboratory of Land Surface Process and Climate Change in Cold and Arid Regions, Northwest Institute \\ of Eco-Environment and Resources, Chinese Academy of Sciences, Lanzhou 730000, China; \\ anyingying@lzb.ac.cn (Y.A.); zhaolin_110@lzb.ac.cn (L.Z.); zgli@lzb.ac.cn (Z.L.); \\ wangshaoying@lzb.ac.cn (S.W.); sly@lzb.ac.cn (L.S.); chenhao@lzb.ac.cn (H.C.); gwli@lzb.ac.cn (G.L.); \\ mayingsai@lzb.ac.cn (Y.M.) \\ 2 Zoige Plateau Wetland Ecosystem Research Station, Northwest Institute of Eco-Environment and Resources, \\ Chinese Academy of Sciences, Lanzhou 730000, China \\ 3 College of Earth and Planetary Sciences, University of Chinese Academy of Sciences, Beijing 100049, China \\ 4 Plateau Atmosphere and Environment Key Laboratory of Sichuan Province, School of Atmospheric Sciences, \\ Chengdu University of Information Technology, Chengdu 610225, China; slu@cuit.edu.cn \\ 5 Collaborative Innovation Center on Forecast and Evaluation of Meteorological Disasters, Nanjing University \\ of Information Science and Technology, Nanjing 210044, China \\ * Correspondence: mxh@lzb.ac.cn; Tel.: +86-0931-4967239
}

Received: 11 June 2020; Accepted: 23 July 2020; Published: 31 July 2020

check for updates

\begin{abstract}
Surface albedo is a crucial parameter in accurately and quantitatively estimating energy and water budget on the Tibetan Plateau (TP) and is also one of the largest radiative uncertainties in land surface modelling attempts. Based on an 8-year ground-based observation of the surface albedo over typical alpine meadows at Maqu and Maduo sites in the eastern TP, the performance of surface albedo products of Global LAnd Surface Satellite (GLASS) and Moderate Resolution Imaging Spectroradiometer (MODIS) in describing albedo variations at daily, 8-day, seasonal timescales, and during different special weather conditions were analyzed. Compared with the ground-based observation in Maqu, the 8-day albedo products from GLASS and MCD43B3 present maximum negative biases of -0.030 and -0.027 at Maqu, respectively. The black-sky albedo (BSA) of GLASS product coincides well with the ground-based observation in Maduo, with root mean square error (RMSE) of 0.092 and correlation coefficient (R) of 0.833, whereas that of MCD43B3 had an RMSE of 0.072 and $R$ of 0.752 . However, they are underestimated when the albedo is greater than 0.4 . At the seasonal timescale, the BSA of GLASS and MCD43B3 underestimated the ground-based observation of Maqu by 0.015 in summer, while their white-sky albedo (WSA) are slightly overestimated and closer to the ground-based observation. In daily timescale, the response of surface albedo to soil moisture is different in semihumid and semiarid areas in summer. For both sites, the blue-sky-albedo of MCD43A3 has better agreement with the ground-based observation than GLASS and MCD43B3, as it improves the temporal resolution and calculates the albedo by weighting multiple observations within 16 days to be closer to the actual surface. However, even MCD43A3 could not capture the slowdown processes of albedo changes resulted by small snowfall processes or the snow aging due to cloud cover and inversion algorithms.
\end{abstract}

Keywords: albedo evaluation; snow cover; GLASS; MODIS; Tibetan Plateau 


\section{Introduction}

Surface albedo is defined as the ratio of reflected shortwave radiation to the incident solar radiation at the surface, which directly determines the proportion of net radiation absorbed by the ground, thereby affecting the energy and water exchange between the land and atmosphere [1-3]. Thus, it is critical to land surface processes simulation and affects the local weather status and the Asian summer monsoon through temporal and spatial changes [4,5]. Moreover, it is also one of the largest radiative uncertainties related to modelling attempts $[6,7]$.

Many sets of global-scale surface albedo products have been produced based on satellite sensor observations, including Moderate Resolution Imaging Spectroradiometer (MODIS), Multi-angle Imaging SpectroRadiometer (MISR), Polarization and Directionality of the Earth's Reflectances (PLODER), Medium Resolution Imaging Spectrometer (MERIS), and Cloud and the Earth's Radiant Energy System (CERES). Whether directly using the remote sensing albedo products, improving climate models and land surface processes based on these products, or studying global changes and ecological environments, it is required to have sufficient objective understanding of the accuracy of albedo products themselves. Over the past decades, researchers have made great efforts on improving surface albedo retrieval algorithms for various remote sensing satellites/sensors, such as spectral albedo from atmospherically corrected cloud-cleared multiangular reflectance observations by inverting the Bidirectional Reflectance Distribution Function (BRDF) model and angular integration [8-11]. A direct-estimation algorithm for mapping daily land-surface broadband albedo from MODIS data is used when broadband albedo rapidly changes [12] and an implied angular shape refinement of the surface hemispherical directional reflectance factor (HDRF) in all MISR wavelengths is required [13]. The albedo and dynamic features of land surfaces on a small timescale are retrieved by the multisensor combined BRDF inversion (MCBI) model [14]. Wu et al. [15] showed that the Multi-source Data Synergized Quantitative Remote Sensing Production system (MuSyQ) albedo is a better correlated with ground measurement in the Heihe River Basin, China, with root mean square error (RMSE) of 0.033 and square of correlation coefficient $\left(R^{2}\right)$ of 0.893 , because it has a higher revisit frequency and a denser angular sampling for robust BRDF retrieval. So far, a lot of researches on surface albedo products were performed in Europe [16,17], the United States [18-21], Greenland [22-24], and on a global scale [25-27]. But verifications of the Global LAnd Surface Satellite (GLASS) and MODIS were conducted less in Asia, especially over the Tibetan Plateau (TP). Only an extensive, objective, and quantitative evaluation of remote sensing albedo products can provide the possibility of further improving their models, methods, and algorithms, thereby expanding their range of application and stability.

The Tibetan Plateau (TP), which covers an area of approximately $2.5 \times 10^{6} \mathrm{~km}^{2}$ with a mean elevation of more than $4000 \mathrm{~m}$, is the most prominent and complex terrain in the world. Through its thermal and dynamic forcing, it modulates weather and climate over the Asia-Pacific region [28-30]. Recently, a study highlights the need to understand how atmospheric variability is rapidly modulated by fast snow cover-induced albedo changes [31]. Due to its importance, several examinations of remote sensing albedo products have been conducted. An et al. [32] evaluated the remote sensing products of GLASS, MODIS, and GlobAlbedo over the TP, and found that GlobAlbedo albedo was greater than the mean ground-based observation by 0.048 , while the GLASS and MODIS were underestimated. Wang et al. [33] used the ground measurement of albedo at the Gaize Automatic Weather Station from January 2001 to July 2003, revealing that the 16-day-averaged snow-free albedo matched the MODIS-derived albedo well, but was little larger than MODIS albedo in 2001 and less in 2003 due to the snow cover in winter. The snow is rather heterogeneous across the TP, predominantly the shallow snow cover with short duration [34]. The latitude of the TP is low and the solar radiation is strong throughout the year, causing the snow ablates quickly on clear and dry spring and winter days [35]. $\mathrm{Pu}$ et al. [36] stated that the total error of MODIS snow data on TP is about $10 \%$, and very shallow snow depths $(<5 \mathrm{~cm})$ cause omission errors. The characteristics, depth, and duration of snow cover have an important impact on the rapid changes of surface albedo on the TP, but the performance of 
the products in describing the changes of albedo responses to rapid snow cover changes or different weather conditions such as rainfall and snowfall events are still left to be evaluated.

This article is an advanced study which pays more attention on how about the products reflect the albedo changes in different time scales, particularly on how they performed under different weather situation. A recent study illustrated that the rapid change of albedo caused by the snowfall and the quick snow melting on the TP in early spring and winter can be very important for 3-7 days' short-term climate prediction [31]. Thus, this is the first step of our work to see how the satellite albedo reflect the snowfall- and melting-induced albedo changes, and then, in the second step, a better time varying albedo products will be used to update the lower boundary condition to actively perform its influence on the atmospheric circulation. In this study, we further assessed the MODIS daily albedo product to investigate the albedo changes under special weather conditions and within an 8-day timescale and its relationship with air temperature and $5 \mathrm{~cm}$ soil moisture, as well as the main causes of surface albedo product bias were analyzed in detail. The study is outlined as follows. Section 2 describes the remote sensing albedo products, in situ measurements, and methods used in this study. Section 3 provides a performance assessment of the remote sensing albedo products. Section 4 presents a discussion on analysis results and methods. Section 5 concludes with a summary of the findings.

\section{Data and Methods}

\subsection{Remote Sensing Albedo Products}

\subsubsection{GLASS Product}

Global LAnd Surface Satellite (GLASS) is a land surface product developed by Beijing Normal University. GLASS surface albedo product has stable, high-quality data output, and is produced in two steps. The first step is the traditional remote sensing inversion, which is to extract the surface albedo from the remote sensing observation data by inverting the surface-atmospheric radiation transmission model. Then, a variety of primary albedo products are fused and filled by filtering methods to form high-quality fused products. GLASS establishes advanced high-level direct estimation algorithms including Angular Bin and statistics-based temporal filter (STF) with multisource remote sensing observations [37]. The Angular Bin algorithm establishes a linear regression equation between surface directional reflectance and shortwave broadband albedo, specifically the shortwave white-sky albedo and black-sky albedo corresponding to the solar angle at local noon. The STF algorithm regards different intermediate products as samples of the "true" surface albedo with an inversion error and time discrepancy [38]. The fourth edition product named GLASS02A06 is used in this study, which extends to black-sky albedo (BSA), white-sky albedo (WSA) at noon local time, and quality control information in the visible (VIS) and near-infrared (NIR) bands, except for short waves (Table 1). The data can be downloaded for free at http://glass-product.bnu.edu.cn:8088/.

\subsubsection{MODIS Products}

Moderate Resolution Imaging Spectroradiometer (MODIS) is a key instrument of the NASA Earth Observation System (EOS) aboard the Terra and Aqua satellites with high spatial and temporal resolution $[39,40]$. The albedo product number of sinusoidal projections is MCD43, which provides the BSA and WSA albedos for three broadbands and seven spectral bands (Table 1). The inversed algorithm of MCD43B3 and MCD43A3 products applies the linear kernel-based BRDF model driven by the RossThick-LiSparse-Reciprocal, based on the multiangle observation data accumulated by the change of satellite-surface-sun relative position over a 16-day window [41,42].

MCD43B3 Version 5 (V005) data set is a level-3 gridded product, providing a standard suite of albedo at $1 \mathrm{~km}$ resolution. It is widely used in various research fields [19-22,32,33]. MCD43A3 (V006) albedo with a spatial resolution of $500 \mathrm{~m}$ is the latest version of albedo product, weighting observations to estimate BRDF/Albedo on the ninth day of the 16-day period and improving the temporal resolution 
from 8-day of V005 to 1-day. Its quality information is provided in the corresponding MCD43A2 data file. The data was downloaded from the https:/ladsweb.modaps.eosdis.nasa.gov/search/order/.

Table 1. Features of the surface albedo products of Global LAnd Surface Satellite (GLASS), MCD43B3, and MCD43A3.

\begin{tabular}{|c|c|c|c|}
\hline Products & GLASS & MCD43B3 & MCD43A3 \\
\hline Sensors & NOAA/AVHRR, MODIS & MODIS & MODIS \\
\hline Satellites & NOAA, Terra, and Aqua & Terra and Aqua & Terra and Aqua \\
\hline $\begin{array}{l}\text { Included surface } \\
\text { albedo data }\end{array}$ & $\begin{array}{c}\text { BSA and WSA in three } \\
\text { broadbands: shortwave } \\
(0.3-5.0 \mu \mathrm{m}), \mathrm{VIS}(0.3-0.7 \mu \mathrm{m}), \\
\text { and NIR }(0.7-5.0 \mu \mathrm{m})\end{array}$ & $\begin{array}{c}\text { BSA and WSA in three } \\
\text { broadbands: shortwave } \\
(0.3-5.0 \mu \mathrm{m}), \mathrm{VIS}(0.3-0.7 \mu \mathrm{m}), \\
\text { and NIR }(0.7-5.0 \mu \mathrm{m}) \text {; and seven } \\
\text { spectral bands: } 659,865,470 \\
555,1240,1640, \text { and } 2130 \mathrm{~nm}\end{array}$ & $\begin{array}{c}\text { BSA and WSA in three } \\
\text { broadbands: shortwave } \\
(0.3-5.0 \mu \mathrm{m}), \text { VIS }(0.3-0.7 \mu \mathrm{m}), \\
\text { and NIR }(0.7-5.0 \mu \mathrm{m}) ; \text { and seven } \\
\text { spectral bands: } 659,865,470, \\
555,1240,1640, \text { and } 2130 \mathrm{~nm}\end{array}$ \\
\hline Projection & Sinusoidal equal area & Sinusoidal equal area & Sinusoidal equal area \\
\hline Spatial resolution & $1 \mathrm{~km}$ & $1 \mathrm{~km}$ & $500 \mathrm{~m}$ \\
\hline $\begin{array}{l}\text { Temporal } \\
\text { resolution }\end{array}$ & 8-day & 8-day & daily \\
\hline Algorithm & Direct estimation & BRDF modeling & BRDF modeling \\
\hline $\begin{array}{l}\text { BRDF synthesis } \\
\text { period }\end{array}$ & 1-day & 16-day & 16-day \\
\hline Temporal range & 2009-2017 & 2009-2017 & 2009-2017 \\
\hline
\end{tabular}

\subsection{In Situ Measurements}

The Zoige Plateau Wetland Ecosystem Research Station (Northwest Institute of Eco-Environment and Resources, Chinese Academy of Sciences, Lanzhou, Gansu, China), established in 2008, is located in the source region of the Yellow River in the eastern TP (Figure 1). To select representative measurement sites, the two steps are followed. First, using the camera carried by unmanned drone aircraft (to obtain overall consistency), satellite remote sensing observations (to maintain uniformity within a relative large area), and the Digital Elevation Model (DEM) data (to explore the complexity of the surrounding topography), a relatively representative and uniform region was selected. Second, three sets of instruments including radiation components, automatic weather stations, and eddy covariance were installed to test the data variance and consistency within this region, and then, the best site was selected. According to the footprint model in Maqu, 90\% turbulent heat fluxes extent is about $200 \mathrm{~m}$, which also shows the rationality of the site selection [43]. Wang et al. [44] examined the radiation balance and the response of albedo to environmental factors above an alpine meadow and alpine wetland surfaces in the eastern TP, using 2014 data collected at the Zoige Plateau Wetlands Ecosystem Research Stations. The standard deviation of elevation $(\sigma)$ is a measure of the variability in elevation within the window. The DEM used to calculate the topographic complexity indices was derived from the NASADEM data released in February 2020, with a spatial resolution of $30 \mathrm{~m}$. The $\sigma$ of 1, 2, and $3 \mathrm{~km}$ away from the ground measurement fields of Maqu and Maduo are 2.33, 5.68, $6.70 \mathrm{~m}$ and 40.94, 61.39, $71.28 \mathrm{~m}$, respectively. This also proves that Maqu site is very flat, and the Maduo area is hilly (Figure 1d,f). In addition, the vegetation cover types of the ground measurement sites are consistent with that of the surroundings, obtained using MODIS land cover products with a spatial resolution of $0.05^{\circ}$ from 2001 to 2011 (Figure 1e,g). As a result, the surface of the observation fields of Maqu and Maduo are considered as to be broadly uniform, which are considered to be capable to fully characterize the spatial variance within the small scale and to be potentially homogeneous. 

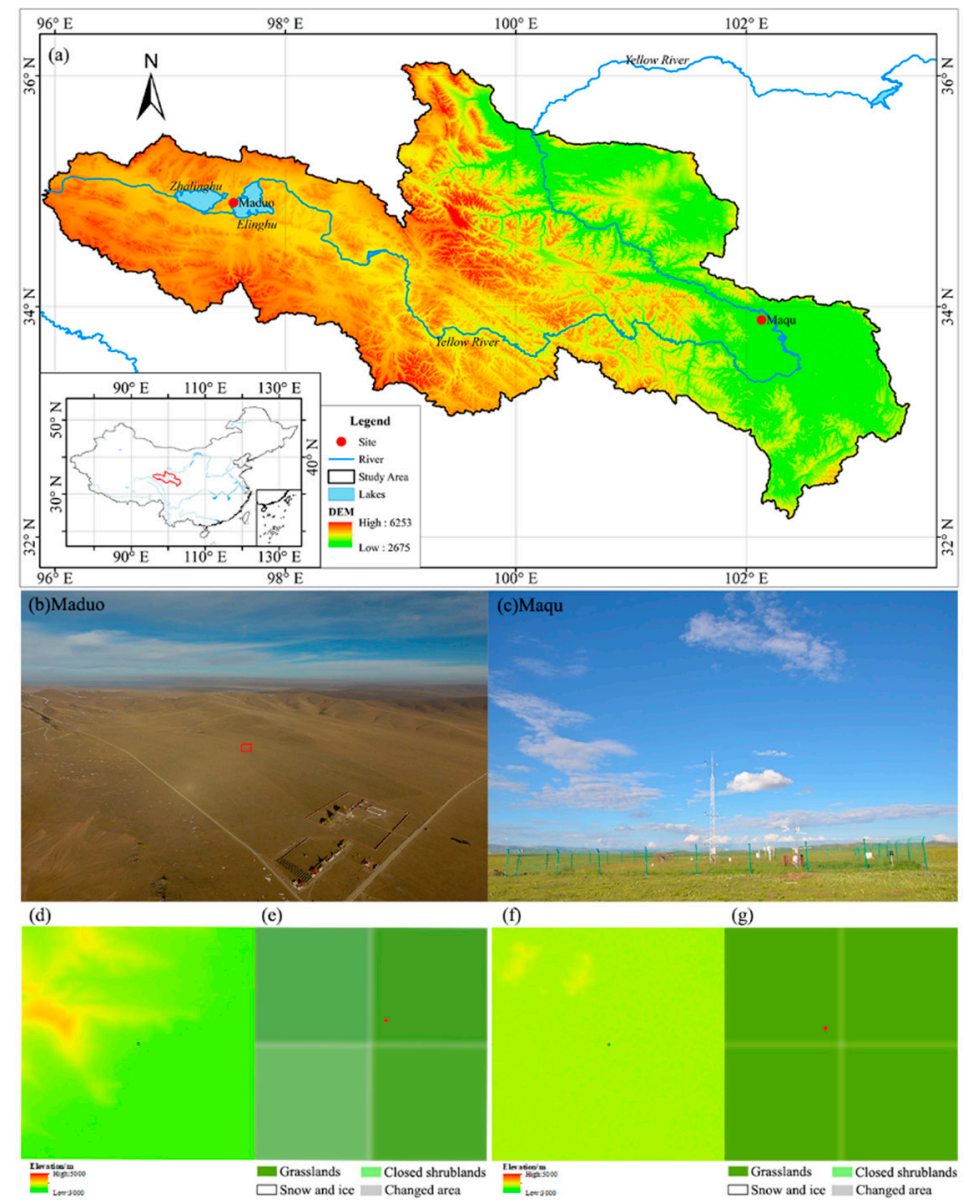

Figure 1. (a) Digital elevation map, with the location of the ground measurement sites marked by red circles, setup of the (b) Maduo and (c) Maqu sites over the alpine meadow, $3 \mathrm{~km}$ elevation distribution and vegetation cover types around $(\mathbf{d}, \mathbf{e})$ Maduo and $(\mathbf{f}, \mathbf{g})$ Maqu sites, respectively.

\subsubsection{Grassland Observation Site in Maqu}

The Maqu site $\left(33^{\circ} 53^{\prime} \mathrm{N}, 102^{\circ} 08^{\prime} \mathrm{E}, 3423\right.$ m.a.s.l.) is typically characterized by an alpine meadow south of the Maqu County (Figure 1a,c). The land surface is uniformly covered by $0.2 \mathrm{~m}$ meadow in the summer and about $0.1 \mathrm{~m}$ in the winter. Its soil type is silt clay loam consisting of $29.8 \%$ sand, $66.7 \%$ silt, and $3.5 \%$ clay in the top $40 \mathrm{~cm}$ [43]. The annual mean temperature from 1967 to 2010 is $1.7^{\circ} \mathrm{C}$ and annual mean precipitation is $600 \mathrm{~mm}$ but there is little snow frequency in winter [44]. The radiation sensor at Maqu site is a CNR1 net radiometer (Kipp \& Zonen, Delft, The Netherlands), including two CM3 pyranometers and two CG3 pyrgeometers, which records data every $30 \mathrm{~min}$ [45]. The parameters of the instrument installed at this site are listed in Table 2. Solar radiation is measured with two CM3 pyranometers, one for measuring incoming solar radiation from the sky and the other facing downward for measuring the reflected solar radiation. From these two pyranometers, albedo, the ratio of reflected and incoming shortwave radiation, can also be determined. The pyrgeometers for measuring far infrared radiation are not involved, as they do not measure shortwave solar radiation. This unitless value ranges between 0 and 1 . Checking this can be used as a tool for quality assurance of data. All instruments are calibrated annually to ensure their reliability. The CNR1 should be calibrated using the calibration factor added to each pyranometer or by running a higher standard parallel with it over a 2-day period and then, comparing the results on a sunny day. 
Table 2. Basic information of ground measurement sites and specific parameters of observational instruments.

\begin{tabular}{ccc}
\hline Site & Maqu & Maduo \\
\hline Location & $33^{\circ} 53^{\prime} \mathrm{N}, 102^{\circ} 08^{\prime} \mathrm{E}$ & $34^{\circ} 54^{\prime} \mathrm{N}, 97^{\circ} 33^{\prime} \mathrm{E}$ \\
\hline Elevation & $3423 \mathrm{~m}$ & $4300 \mathrm{~m}$ \\
\hline Climate & Cold humid & Cold semiarid \\
\hline Grassland vegetation & $\begin{array}{c}\text { Rheum spp., Oreosolen wattii, Lagotis } \\
\text { brachystachya, Saussurea graminea, etc. }\end{array}$ & $\begin{array}{c}\text { Stipa purpurea, Urtica hyperborea, } \\
\text { Microcaryum pygmaeum, Potentilla bifurca, etc. }\end{array}$ \\
\hline Measurement height & $1.5 \mathrm{~m}$ & $1.5 \mathrm{~m}$ \\
\hline Sensor type & CNR1 net radiometer & CNR1 and CNR4 net radiometers \\
\hline Sensor manufacture & Kipp \& Zonen (Delft, The Netherlands) & Kipp \& Zonen (Delft, The Netherlands) \\
\hline Spectral range & $\begin{array}{c}0.3-50 \text { micrometers (including shortwave } \\
\text { radiation of } 0.3-2.8 \mu \mathrm{m})\end{array}$ & $\begin{array}{c}0.3-50 \text { micrometers for CNR1 and } \\
0.0 \text { m for CNR4 (including shortwave } \\
\text { radiation of } 0.3-2.8 \mu \mathrm{m} \text { ) }\end{array}$ \\
\hline Uncertainty of pyranometer & $\pm 10 \%$ (day total) & $<5 \%$ (day total) for CNR4's pyranometer \\
\hline
\end{tabular}

\subsubsection{Grassland Observation Site in Maduo}

The Maduo site $\left(34^{\circ} 54^{\prime} \mathrm{N}, 97^{\circ} 33^{\prime} \mathrm{E}, 4300\right.$ m.a.s.l.) is located in a grassland about $1.7 \mathrm{~km}$ away from the northwest side of Ngoring Lake. There are no fences in the ground measurement field of Maduo, and the vegetation is the same as the surrounding area, with a height of about $0.05-1.10 \mathrm{~m}$ (Table 2). The landscape is homogeneous and wide open with soil dominated by alpine meadow soil, which is rich in nitrogen, phosphorus, and potassium. A few hills with relative height of 50 to $100 \mathrm{~m}$ are distributed about $1 \mathrm{~km}$ away from the northwest. The instrument for measuring radiation in the site is CNR1 net radiometer (Kipp \& Zonen, Delft, The Netherlands) before June 2014, and then CNR4 net radiometer (Kipp \& Zonen, Delft, The Netherlands) is used. The CNR1 instrument is the same as that installed at Maqu site. The CNR4 is a four-component net radiometer, consisting of a pyranometer pair, one facing upward and the other facing downward, for measuring shortwave solar radiation [46]. The measured values of these two pyranometers are used to determine the albedo. The output is expressed in $\mathrm{W} / \mathrm{m}^{2}$. Unlike the CNR1, four probes in the CNR4 have different sensitivity values, which make each measurement from four sensors more accurate. The calibration of albedo from CNR4 is similar to CNR1. Radiation data are recorded every $30 \mathrm{~min}$ by the pyranometers installed at a height of $1.5 \mathrm{~m}$ at the site.

\subsection{Methods}

\subsubsection{Calculation of 8-Day Average Albedo of GLASS and MCD43B3}

From the data, unreasonable albedos measuring $<0$ and $>1$ in the ground-based observations were removed. As the GLASS albedo is calculated at noontime, the ground-based daily mean albedo is the hourly average from 12:00 p.m. to 2:00 p.m. local time in Maqu and Maduo. The albedos of the two pixels closest to the Maqu and Maduo sites in the GLASS and MCD43B3 were averaged, respectively. The substantial aggregation method of GLASS albedo product is used to calculate the arithmetic mean of the valid albedo data selected before and after 8 days (total duration of 16 days) of the specific time. In other words, when comparing the surface albedo averaged over 8 days, the daily albedo on the 9th day is the composite result of the daily surface albedo from day 1 to 16 . For an accurate comparison and analysis, the ground-based observations were processed into the 8-day average data and were consistent with the temporal resolution of the GLASS product. Considering the effect of snow on albedo, if there were snow cover during most days of the 16-day period, the albedo at noon is greater than 0.4 and only snow-covered pixels were used for the 8-day albedo retrieval [47].

The surface albedo products of GLASS and MCD43B3 directly supply the BSA and WSA with $1 \mathrm{~km}$ spatial resolution, 8-day temporal resolution, and sinusoidal projection, whereas the synthesis 
periods between GLASS and MCD43B3 are inconsistent. To reduce uncertainty from different data sources, the inversion data during the 16-day period of the sequential accumulation periods from the 9th day of GLASS is compared with that from the 1st day of MCD43B3 and the inversion data from the 17th day of GLASS is compared with that from the 9th day of MCD43B3, and so on.

The surface albedo under actual atmospheric conditions should be weighted based on the fraction of the diffuse radiation to the total radiation and aerosol optical depth. However, it is difficult to obtain the aerosol optical depths at Maqu and Maduo sites. Also, there is no such information in GLASS and MCD43B3 albedo products. Hence, their BSA and WSA albedos were directly evaluated by observations in this study.

\subsubsection{The Blue-Sky-Albedo of MCD43A3}

First, it needs to calculate the proportion of diffuse illumination, according to the solar zenith angle (SZA) at noon provided by BRDF_Albedo_LocalSolorNoon in the MCD43A2 (V006) product. Then, the linear weighting method is used to compute the blue-sky-albedo (actual surface albedo) using the BSA and WSA albedos of the shortwave provided by the MCD43A3 product (Equations (1) and (2)) $[48,49]$.

$$
\begin{aligned}
& r=0.122+0.85 \exp (-4.8 \cos \theta) \\
& \alpha_{\mathrm{GA}}=\alpha_{\mathrm{BSA}} \times(1-\mathrm{r})+\alpha_{\mathrm{WSA}} \times \mathrm{r}
\end{aligned}
$$

where $r$ is the proportion of diffuse illumination, $\theta$ is the SZA, $\alpha_{G A}$ is the actual surface albedo, $\alpha_{B S A}$ is the BSA, and $\alpha_{\text {WSA }}$ is the WSA.

The spatial representativeness of the selected ground observation site is firstly judged. For the ground-based observation data sets with sufficient spatial representation, the accuracy of the remote sensing products to be verified is usually obtained by direct verification. The uniform grasslands at Maqu and Maduo sites perfectly meet this requirement. The albedos of the two pixels closest to the Maqu and Maduo sites in MCD43A3 were averaged.

\subsubsection{Interpretation of Statistical Metrics Used}

The RMSE, bias, and R had been regularly used as the standard statistical metrics to measure product performance for many years. They are calculated for the data set as

$$
\begin{gathered}
\text { RMSE }=\sqrt{\frac{\sum_{\mathrm{i}=1}^{\mathrm{n}}\left(\mathrm{X}_{\text {observed }, \mathrm{i}}-\mathrm{X}_{\text {estimate }, \mathrm{i}}\right)^{2}}{\mathrm{n}}} \\
\text { bias }=\mathrm{x}_{\text {observed, } \mathrm{i}-\mathrm{x}_{\text {estimate }, \mathrm{i}}} \\
\mathrm{R}=\frac{\sum_{\mathrm{i}=1}^{\mathrm{n}}\left(\mathrm{x}_{\mathrm{i}}-\overline{\mathrm{x}}\right)\left(\mathrm{y}_{\mathrm{i}}-\overline{\mathrm{y}}\right)}{\sqrt{\sum_{\mathrm{i}=1}^{\mathrm{n}}\left(\mathrm{x}_{\mathrm{i}}-\overline{\mathrm{x}}\right)^{2} \sum_{\mathrm{i}=1}^{\mathrm{n}}\left(\mathrm{y}_{\mathrm{i}}-\overline{\mathrm{y}}\right)^{2}}}
\end{gathered}
$$

in which $\mathrm{X}$ and $\mathrm{y}$ stand for the surface albedo, $\mathrm{x}_{\text {observed }}$ and $\mathrm{x}_{\text {estimate }}$ are the ground-based and satellite-based albedos, and $\mathrm{n}$ is the number of data set.

\section{Results}

\subsection{Evaluation of 8-Day Average Albedo}

The annual magnitude of ground-based albedo in Maqu area is smaller than that of Maduo, because there are relatively more snowfall events in Maduo (Figure 2a). Nevertheless, on the inversions beginning on the 49th day of 2014 and the 9th day of 2015, the ground-based albedo rose to 0.67 and 0.65, respectively. Particularly, the albedo at 12:00-2:00 p.m. on 17 February 2014, reached 0.83-0.88. Shi and Liang [50] found that the albedo increase over TP is highly correlated with the increase in snow 
cover. The WSA and BSA of MCD43B3 are 0.66 on the 41st and 49th day of 2014 and only 0.20 on the 9th day of 2015, while those of GLASS are 0.20 and 0.24 on the 49th day of 2014 and the 9th day of 2015, respectively. GLASS used the STF algorithm that performs time series smoothing and filters fusion of surface albedo, which ignores sharp increase [51]. GLASS's BSA albedo exhibited the highest RMSE of 0.055 and smallest $R$ of 0.327 from January 2009 to June 2017, while the WSA and BSA of MCD43B3 obtained data closer to the ground-based observation with RMSE of 0.055 and R of 0.503 (Table 3 and Figure 3a). Compared to the ground-based observation at Maqu, GLASS and MCD43B3 albedo products have the maximum negative biases of -0.030 and -0.027 , especially in spring (Figure $4 \mathrm{a}$ ). Less snow frequency at Maqu in winter, combined with strong solar radiation, causes the snow to melt quickly. Therefore, the ground-based albedo in 8-day greater than 0.4 is not very large, resulting in the bias of albedo products.

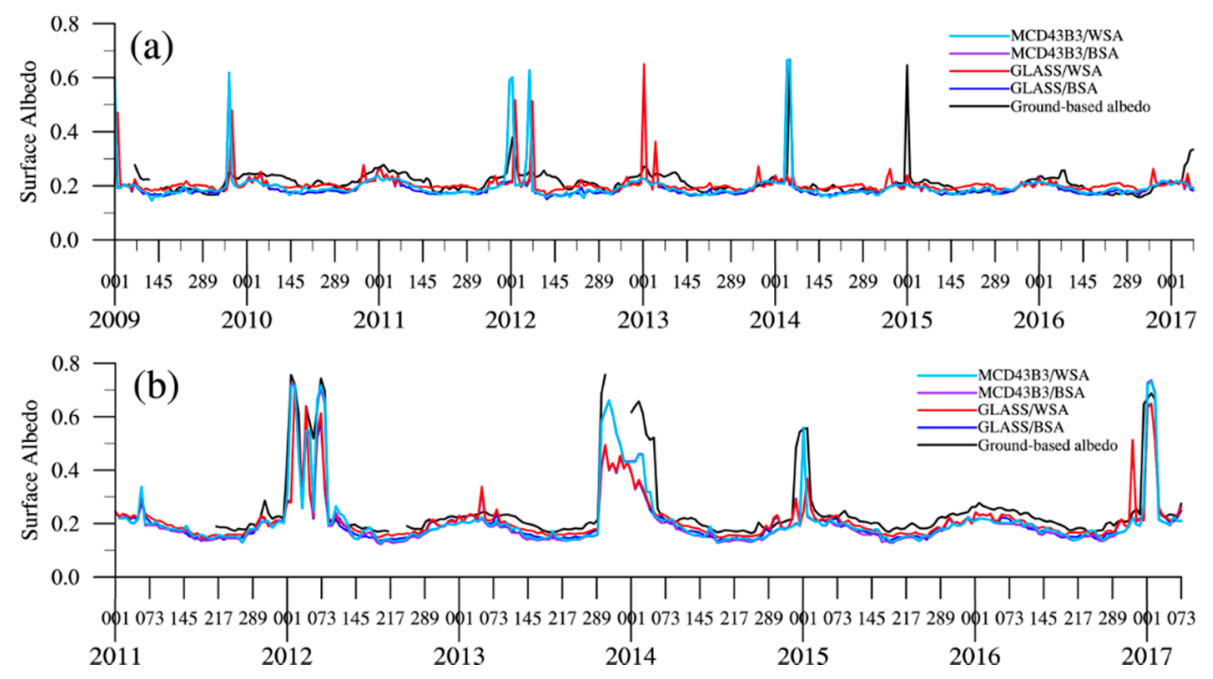

Figure 2. Comparison of the 8-day average albedo over the years between the GLASS, MCD43B3 albedo, and ground-based observation at (a) Maqu site from January 2009 to June 2017 and (b) Maduo site from January 2011 to June 2017.

Table 3. Root mean square error (RMSE) and bias between GLASS, MCD43B3 albedo, and ground-based observation at (Figure 2a) Maqu site from January 2009 to June 2017 and (Figure 2b) Maduo site from January 2011 to June 2017.

\begin{tabular}{ccccc}
\hline & \multicolumn{2}{c}{ Maqu Site } & \multicolumn{2}{c}{ Maduo Site } \\
\cline { 2 - 5 } & RMSE & Bias & RMSE & Bias \\
\hline GLASS/BSA & 0.055 & -0.030 & 0.092 & -0.054 \\
GLASS/WSA & 0.052 & -0.026 & 0.088 & -0.045 \\
MCD43B3/BSA & 0.055 & -0.027 & 0.072 & -0.050 \\
MCD43B3/WSA & 0.055 & -0.027 & 0.070 & -0.046 \\
\hline
\end{tabular}

Unlike Maqu site, the ground-based albedo at the Maduo site has more obvious seasonal cycle, ranging from 0.16 in summer to 0.76 in winter (Figure 2b), and the high values appearing in time series may be closely associated with snow. The appearance of snow in the inversions from the 9th to 25th day of 2012, 1st to 49th day of 2014, and 1st to 9th day of 2015 quickly increased the albedo to around 0.6. Particularly, the 16-day albedo from the 9th day of 2012 and 313rd day of 2013 reached 0.76. GLASS and MCD43B3 albedo significantly increased during these periods, but GLASS is underestimated. At Maduo site, the annual negative bias, RMSE, and R between the ground-based albedo and WSA and BSA of GLASS are 0.019-0.073, 0.026-0.128, and 0.514-0.922, while those of MCD43B3 are 0.015-0.076, 0.040-0.137, and 0.387-0.964, respectively (Figures 3b and 4b). The WSA and BSA of GLASS product coincide well with the ground-based observation in Maduo, with the 
RMSE of 0.088 and 0.092 and $R$ of 0.830 and 0.833 , respectively. And the WSA and BSA of MCD43B3 have the RMSE of 0.069 and 0.072 and $R$ of 0.743 and 0.752 , respectively. The results demonstrate that GLASS albedo is comparable to MCD43B3 albedo in capturing the variation of surface albedo. The temporal and spatial resolutions between them are the same, and the error caused by the scale difference is small. However, the 8-day average albedo of remote sensing products have negative biases and reduced accuracy in characterizing high values of surface albedo.
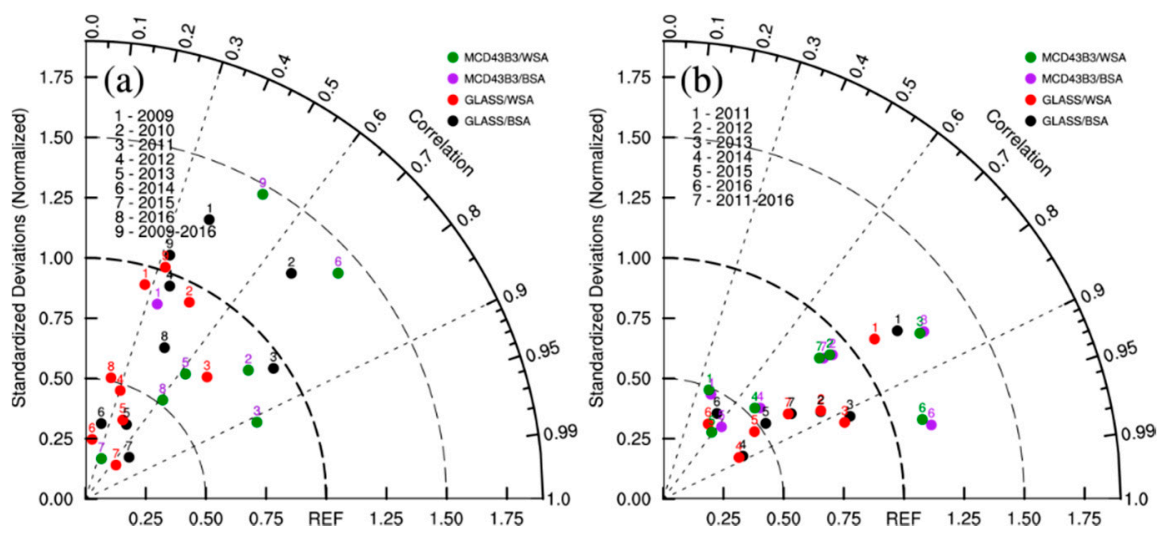

Figure 3. Taylor diagrams of the statistics of the 8-day average albedo of surface albedo products and ground-based observation at (a) Maqu and (b) Maduo sites.
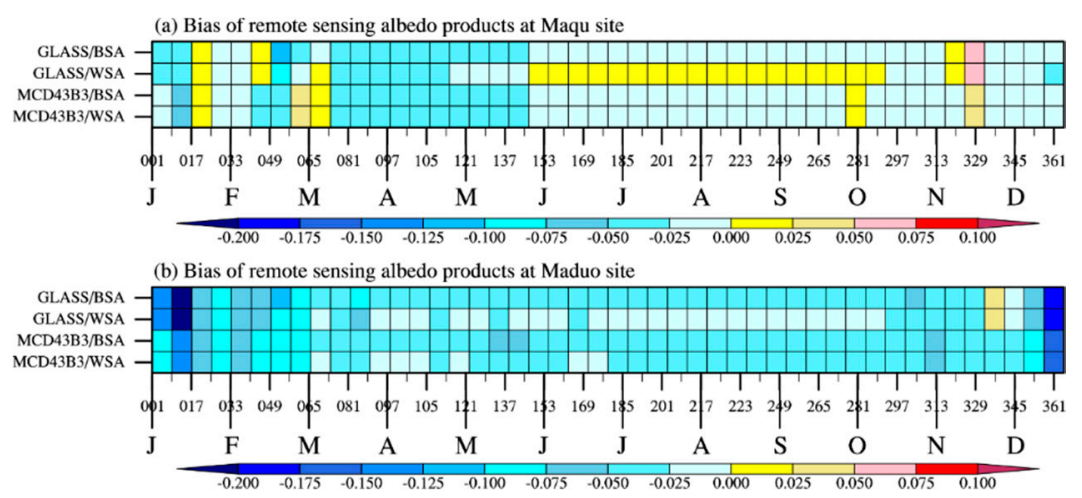

Figure 4. The biases between remote sensing albedo products and ground-based observation at (a) Maqu and (b) Maduo sites.

\subsection{Seasonal Distribution of 8-Day Albedo}

Surface albedo is a dynamic parameter influenced by the vegetation phenology, soil moisture, soil color, surface roughness, SZA, cloud, snow cover, etc. [52-55]. Figure 5 shows the relationship in the 8-day albedo between satellite-based albedo and ground-based observation in different seasons. At Maqu site, the ground-based seasonal variation of surface albedo is in the order of winter $>$ spring >autumn > summer with means of $0.25,0.22,0.18$, and 0.19 , respectively. The ground-based albedos vary with the largest range in winter (0.20-0.67) and the smallest in summer (0.17-0.22), while the satellite-based albedo are $0.18-0.67$ and $0.15-0.23$, respectively. Massive albedo data have good agreement with the ground-based observation of Maqu. In summer, the BSA of GLASS and MCD43B3 underestimated a value of about 0.015 , while their WSA are slightly overestimated and closer to the ground-based observation. GLASS and MCD43B3 products provide both WSA-diffuse reflectance and BSA-direct reflectance, i.e., surface albedo on sunny and cloudy days. In spring and summer, apparent diurnal variations of clouds and precipitation cells were observed on the TP, and the amplitude of diurnal cloud activity fluctuates on intraseasonal time scales [56]. Generally, many convective-type clouds in Maqu develop quickly after 11:00 a.m. local time and exist until mid-night in summer. The transit time of MODIS in the area is approximately 1:00 p.m. local time, and its monitoring is 
significantly affected by clouds. And if the atmospheric conditions are hazy, the atmospheric correction algorithm may introduce error in the high-level products of GLASS and MODIS [17]. A few albedos of GLASS and MCD43B3 in winter have overestimation, the maximum bias of GLASS albedo occurred in January and February of about 0.13 , while that of MCD43B3 is 0.14 in January. The atmospheric correction is performed by individual aerosol estimates for each data point in the algorithm, while a static model is currently employed in the land-based analysis operational system [57]. Furthermore, the SZA on the TP in winter is large. The accuracy of the MCD43B3 albedo decreases significantly when the SZA exceeds $70^{\circ}[20,58]$.
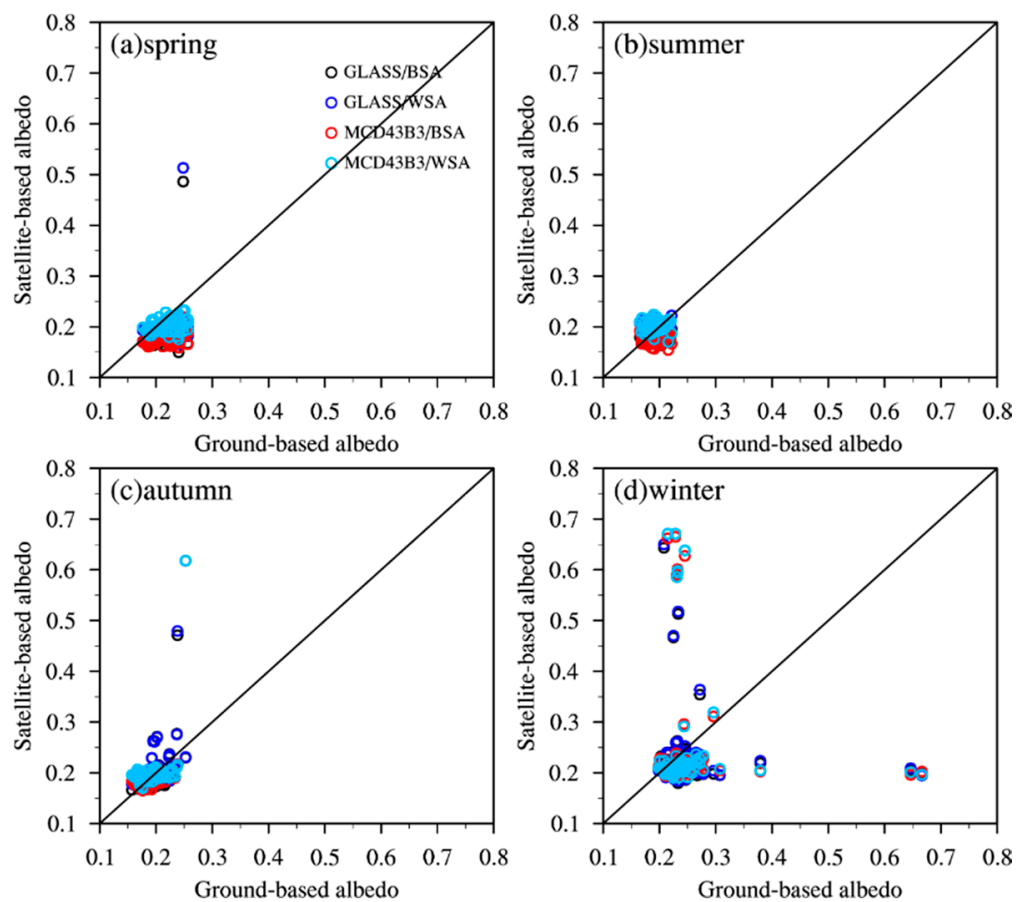

Figure 5. Scatter plots of seasonal changes in albedo for GLASS, MCD43B3, and ground-based at Maqu site over the years during (a) spring, (b) summer, (c) autumn, and (d) winter.

The 8-day average albedo based on the ground observation at the Maduo site in spring, summer, autumn, and winter are $0.22,0.18,0.22$, and 0.33 , respectively, indicating the seasonal changes from 2011 to 2016 over the alpine meadow. In spring and autumn, the ground-based albedos are concentrated at $0.19-0.74$ and $0.17-0.21$, respectively. At this time, the WSA and BSA of GLASS and MCD43B3 are distributed at $0.1-0.3$, and they are obviously much smaller when the ground-based albedos are 0.7-0.8 (Figure $6 \mathrm{a}, \mathrm{c}$ ). However, the WSA and BSA of GLASS are less than the mean ground-based observation by 0.031 and 0.042 , respectively, and those of MCD43B3 are 0.046 and 0.053 , respectively. The fluctuation of surface albedo in winter is intuitively clear at Maduo site, and the satellite-based albedos have higher dispersion. The 8-day average albedo of ground-based observation in winter ranges from 0.21 to 0.76 , may be mainly caused by (1) its higher elevations than Maqu, (2) more frequent precipitation, (3) long duration of snow cover, and (4) significant vegetation changes. The maximum biases of GLASS and MCD43B3 albedos from the ground-based observation in winter are 0.155 and 0.171. The "dark-object" method in MCD43B3 product is used in the current operational atmospheric correction algorithms for estimating aerosol optical depth, which fails over nonvegetated regions that often have much larger albedo values, such as snow, ice, and bare soils [59]. It also displays that the STF algorithm in GLASS has some shortcomings, such as the fact that filtering fusion is likely to filter out some sharply changed points, which correspond to the actual situation [60]. 

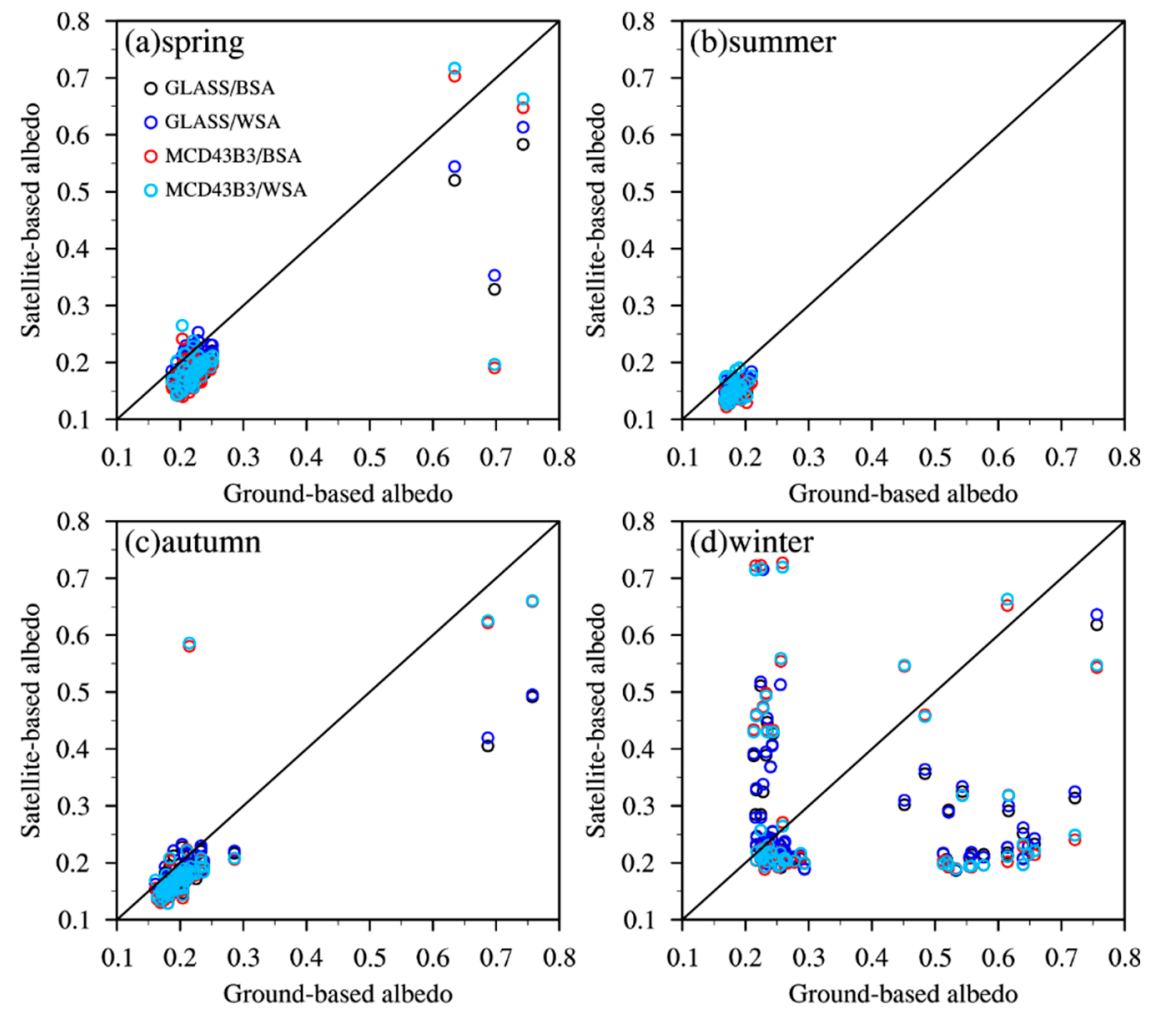

Figure 6. Scatter plots of seasonal changes in albedo for GLASS, MCD43B3, and ground-based at Maduo site over the years during (a) spring, (b) summer, (c) autumn, and (d) winter.

\subsection{Surface Albedo Changes Under Special Weather Conditions}

\subsubsection{Effect of Snowfall on Daily Albedo}

Snow has a high albedo and can modify the ground energy balance [35]. Li et al. [31] have pointed out that the subseasonal variability of TP snow cover is closely related to the subsequent East Asian atmospheric circulation at medium-range time scales (approximately 3-8 days later) during wintertime. However, various snow processes that might be important may be missing or misrepresented. The daily ground-based albedo and satellite-based albedo are used to study the effect of snow. As shown in Figure 7a, continuous snowfall occurred at Maqu site from 1 to 17 January 2015. The maximum ground-based albedo remained 0.21 from 1 to 4 January, while it sharply increased to $0.75,0.72$, and 0.69 , respectively, when the snowfall increased to $2.7 \mathrm{~mm}$ from 5 to 7 January. Meanwhile, the temperatures at noon were less than $0{ }^{\circ} \mathrm{C}$ and the daily average temperatures were below $-10^{\circ} \mathrm{C}$. When the snowfall is small, the ground-based albedo decreases accordingly, about $0.24-0.29$ on $15-17$ January. The albedo of MCD43A3 was 0.19 from January 1 to 5, suddenly increased to 0.66 on the 6th, and continued until the 10th, and then, it decreased to 0.19 . This indicates the superiority of the MCD43A3 albedo product. For the 8-day average albedo, GLASS and MCD43B3 product were less than the ground-based albedo at Maqu site, and the effects of snowfall on albedo were not presented (Figures $4 \mathrm{a}$ and $7 \mathrm{a}$ ). MCD43A3 albedo is more accurate than GLASS and MCD43B3 in the magnitude of albedo during the snowfall periods, embodying its enhanced capability to separate most snow and clouds [61]. However, it missed capturing some short or small snowfall processes such as the slowdown processes of albedo changes from 11 to 16 January. GLASS and MCD43B3 products applied the bidirectional reflection model to calculate reflectance assuming a constant surface in a certain period, leading to the missing or misrepresentation of rapid changes in albedo over TP [60]. The MCD43A3 product is accumulated based on the ground data of 8-day before and after the center day, and then, it assigns different weights according to the distance of the observation date, thereby producing the albedo of the marked date through the weighting of multiple days. 


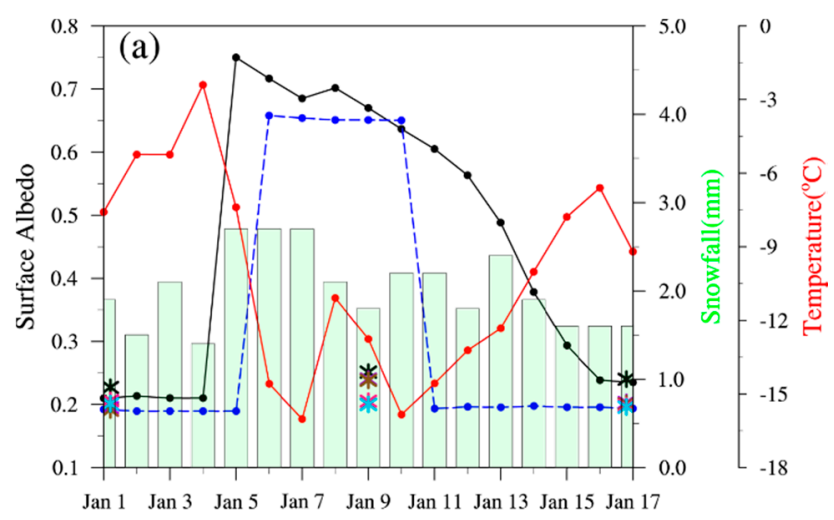

$* 8$-day ground-based albedo $* \mathrm{GLASS} / \mathrm{BSA} * \mathrm{GLASS} / \mathrm{WSA} * \mathrm{MCD} 43 \mathrm{~B} 3 / \mathrm{BSA} * \mathrm{MCD} 43 \mathrm{~B} 3 / \mathrm{WSA}$

$\longrightarrow-$ MCD43A3 $\longrightarrow$ Daily ground-based albedo $\longrightarrow$ Temperature $\square$ Snowfall

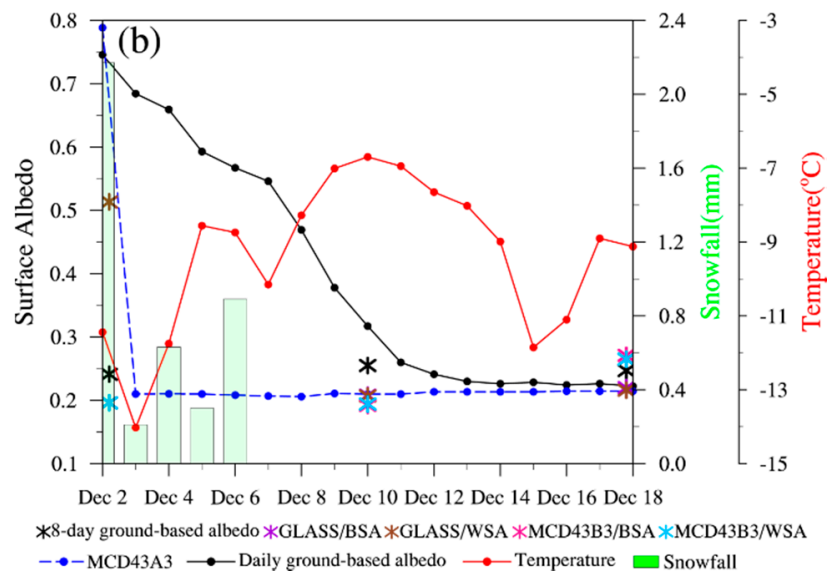

Figure 7. Time series of ground-based albedo, snowfall (units: $\mathrm{mm}$ ), temperature (units: ${ }^{\circ} \mathrm{C}$ ), and satellite-based albedo at the (a) Maqu site from 1 to 17 January 2015 and (b) Maduo site from 2 to 18 December 2016.

Figure $7 \mathrm{~b}$ shows the snowfall in Maduo from 2 to 18 December 2016. On 2 December, the ground-based albedo at noon reached 0.8 with $2.2 \mathrm{~mm}$ snowfall. The daily average albedo rapidly rose from 0.21 to 0.75 , while the temperature dropped from -8.8 to $-11.4{ }^{\circ} \mathrm{C}$. When the snow coverage reached $100 \%$, the ground-based albedo varied from 0.55 to 0.68 . As the temperature increased, the snow began to melt and the ground-based albedo was only around 0.23 from 11 to 18 December. The blue-sky-albedo of MCD43A3 had a similar pattern, which was 0.79 on 2 December, and then maintained at 0.21 . The WSA and BSA of GLASS reduced from 0.51 to 0.21 , highlighting a capture of the slowdown processes of snow albedo. However, the WSA and BSA of MCD43B3 almost presented an opposite trend during this period, increasing from 0.19 to 0.27 , because the algorithm included in it is mainly directed at surfaces with plants and the accuracy of highly reflective snow is not sufficient [60]. When there was no snowfall after 11 December, the daily average albedo based on the ground was $0.22-0.32$. The biases of albedo products from the ground measurements were small, and MCD43A3 albedo performed relatively well with a bias of 0.02 . During the cold season in the absence of snow, the surface is dominated by sparsely dried grass and naked soil, inducing little changes in the albedo. Snow cover makes the surface albedo reach the maximum value of the whole year with albedos of approximately 0.9 for fresh snow and 0.7 for old snow [52]. Snow albedo on the TP depends on the both snow depth and snow density. And the dry-cold snow cover on the TP is characterized by small density and irregular distribution [53]. Although the MODIS sensor has an absolute advantage in snow monitoring, it does not detect snow with depths of less than $0.5 \mathrm{~cm}$ [62]. The patchy snow and reduced snow accumulation by sublimation on TP increase the bias of GLASS and MODIS product [35]. In addition, the snow cover in GLASS and MCD43B3 albedo is determined by the presence of snow for most of the time in 16 days, leading to the removal of snow data in the short term. The MCD43A3 
product uses the snow status weighted to the ninth day instead of the majority snow observations from the 16-day period. These results are reasonable as the MCD43A3 algorithm emphasizes the contribution of the single day of interest more strongly, which enables it to capture subtle changes in surface albedo [15].

\subsubsection{Effect of Rainfall on Daily Albedo}

There were three dominant rainfalls in the Maqu region from 28 July to 13 August 2014, during 28-31 July, 2-8 and 10-13 August. Typical weather conditions with rainfall of more than $20 \mathrm{~mm}$ occurred on the 5 and 8 August 2014. As can be seen in Figure 8a, the ground-based albedo ranged from 0.16 to 0.21 during this period. On August 8, the ground-based albedo decreased from 0.20 to 0.17 with $23.0 \mathrm{~mm}$ rainfall and high soil moisture content of $0.38 \mathrm{~m}^{3} \mathrm{~m}^{-3}$. The albedo then rose to 0.20 in the absence of rainfall, and the soil moisture decreased by $5 \mathrm{~cm}$. The relationship among rainfall, soil moisture content, soil color, and albedo were found to be more complicated on the grassland surface. The blue-sky-albedo of MCD43A3 increased twice on 30 July and 5 August, but did not capture the significant decrease in albedo on July 31 and August 8. The ground-based 8-day average albedo was 0.18-0.19, at which time, the BSA of GLASS and MCD43B3 were underestimated and their WSA were overestimated. The cloud activity on the TP is the most active and complicated in the summer afternoon, and its influence on albedo is dominant and non-negligible [56]. Even with some degree of cloud discrimination provided by MODIS, it does not always reliably separate optically thin cirrus clouds [62].
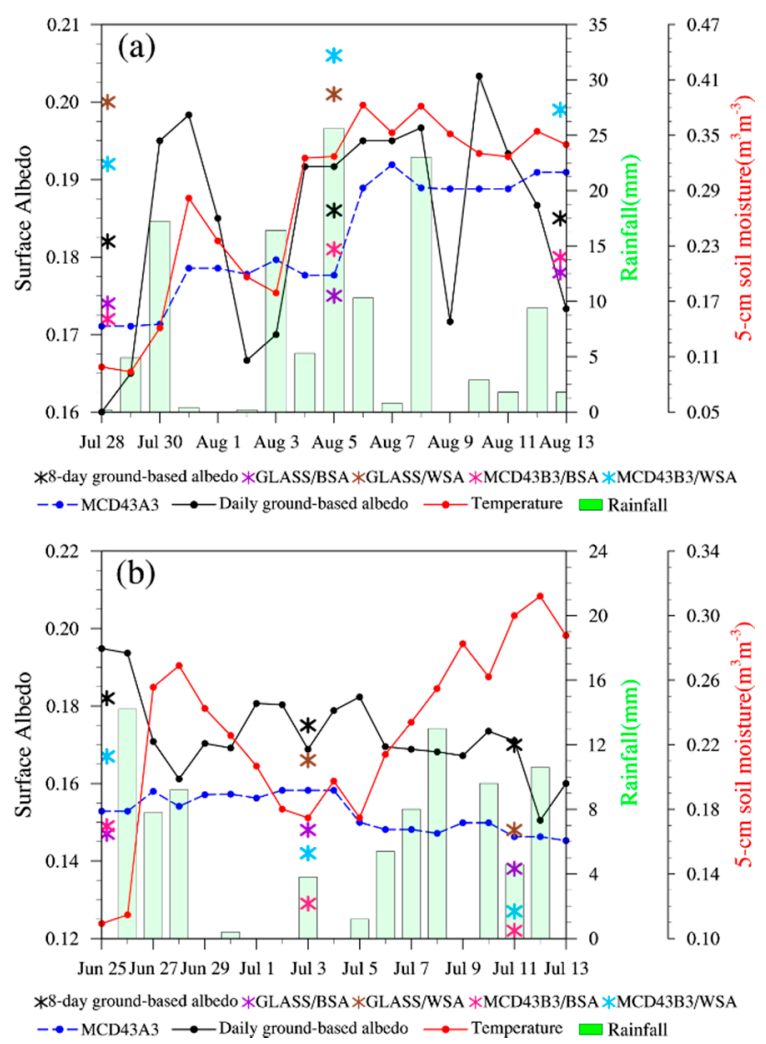

Figure 8. Time series of ground-based albedo, rainfall (units: $\mathrm{mm}$ ), $5 \mathrm{~cm}$ soil moisture (units: $\mathrm{m}^{3} \mathrm{~m}^{-3}$ ), and satellite-based albedo at the (a) Maqu site from 28 July to 13 August 2014 and (b) Maduo site from 25 June to 13 July 2012.

Five rainfall events from 25 June to 13 July 2012, were analyzed at the Maduo site, as shown in Figure $8 \mathrm{~b}$. With a rainfall of $14.2,7.8$, and $9.2 \mathrm{~mm}$, respectively, for $26-28$ days, the ground-based albedo decreased from 0.20 to 0.16 and the $5 \mathrm{~cm}$ soil moisture increased from 0.19 to $0.26 \mathrm{~m}^{3} \mathrm{~m}^{-3}$. The reduction 
in albedo is due to the direct effect of rainfall on soil moisture, which increased the soil moisture content and soil color. These results agreed well with Liu et al. [63] that showed a decrease in albedo when the moisture increased for low soil moisture levels. When rainfall reappeared on July 5 and 10, the $5 \mathrm{~cm}$ soil moisture increased again and the ground-based albedo decreased simultaneously. GLASS, MCD43B3, and MCD43A3 albedos were significantly smaller than the ground-based observation, especially the reduction of MCD43B3 from 0.16 to 0.12 .

The relationship between surface albedo and soil moisture was explored using the daily observation data of ground-based albedo and soil moisture content at the $5 \mathrm{~cm}$ depth from June to August at Maqu site in 2014 and Maduo site in 2012. Figure 9 shows the difference in surface albedo response to soil moisture content in semihumid Maqu and semiarid Maduo regions. The goodness of fit of linear regression of surface albedo and soil moisture in Maqu and Maduo sites were 0.0265 and 0.2772, respectively. The grassland grows well from June to August in the Maqu area, with uniform coverage and high height. The color of the underlying grassland does not change when rainfall occurs, and the effect of soil moisture on the surface albedo is very limited. In semiarid areas, changes in soil moisture affect albedo to a certain extent, due to sparse grass and low height. Besides, the cloud cover will partially mask the dependence of albedo on moisture content [63].
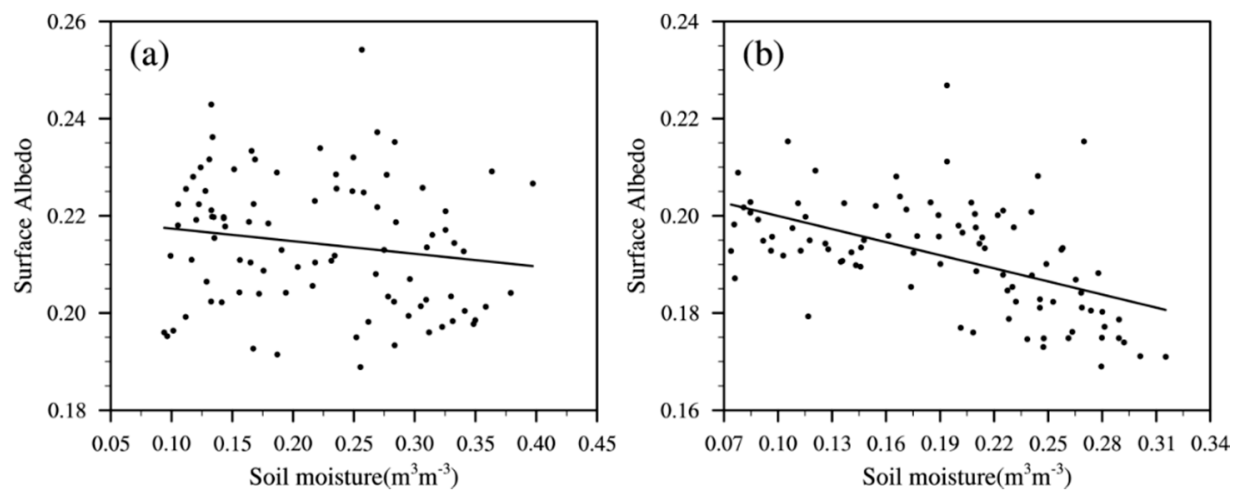

Figure 9. The relationship between daily ground-based albedo and soil moisture (units: $\mathrm{m}^{3} \mathrm{~m}^{-3}$ ) at $5 \mathrm{~cm}$ depth from June to August at (a) Maqu site in 2014 and (b) Maduo site in 2012. The solid line is the fitted relation.

The validation results show that MCD43A3 albedo has better agreement with the ground-based albedo than the GLASS and MCD43B3 for both sites and can also capture the rapid changes of surface albedo in the case of snowfall and rainfall within 8 days. The main reasons are that MCD43A3 product improves the temporal resolution and is more suitable for reflecting the albedo changes in a short period and it calculates the albedo by weighting multiple observations within 16 days to be closer to the actual surface.

\section{Discussion}

Figure 10 shows scatter plots of the 8-day average albedo of ground-based albedo and surface albedo products of GLASS and MCD43B3. At Maqu site, a large amount of the WSA and BSA of GLASS and MCD43B3 were concentrated in the low-value area of the 1:1 line, with small negative bias (Figure 10a,b). Both GLASS and MCD43B3 albedos had individual cases, which were significantly smaller or larger than the ground-based observation of Maqu. The distribution of surface albedo in Maduo site was more discrete. The coincidence of the WSA and BSA of GLASS and MCD43B3 and ground-based observation was relatively high in the low-value range, but they were underestimated when the albedo was greater than 0.4 (Figure 10c,d). The 8-day albedo of this period happened to be averaged based on the number of snow-covered days. When the albedo at Maduo site varied from 0.5 to 0.8 , the WSA and BSA of MCD43B3 were 0.4-0.8 and those of GLASS were only 0.2-0.6. The blue-sky-albedo distribution of MCD43A3 was further verified (Figure 11), and the data were 
concentrated on the 1:1 line when the ground-based albedo were less than 0.3 , but the albedos had varying degrees of dispersion when ground-based observations were greater than 0.4 at Maqu and Maduo sites.
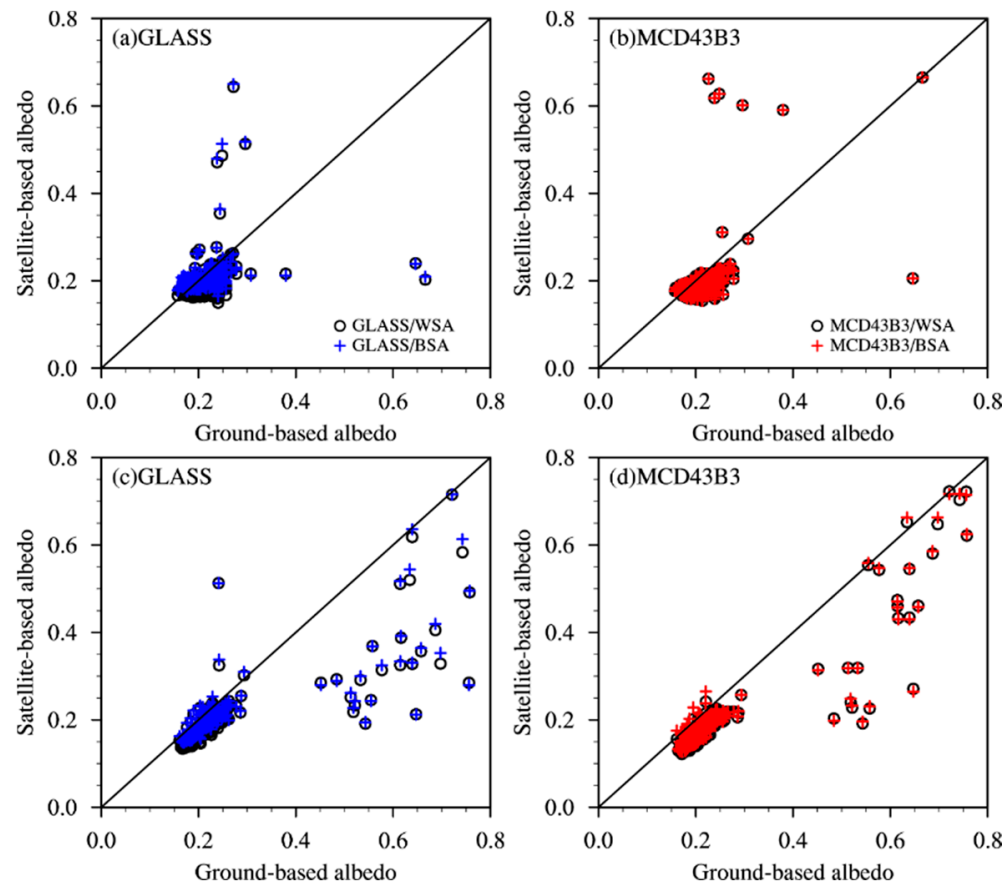

Figure 10. Scatter plots of the 8-day average albedo of ground-based observation and surface albedo products of $(\mathbf{a}, \mathbf{c})$ GLASS and $(\mathbf{b}, \mathbf{d})$ MCD43B3 at Maqu and Maduo sites, respectively.
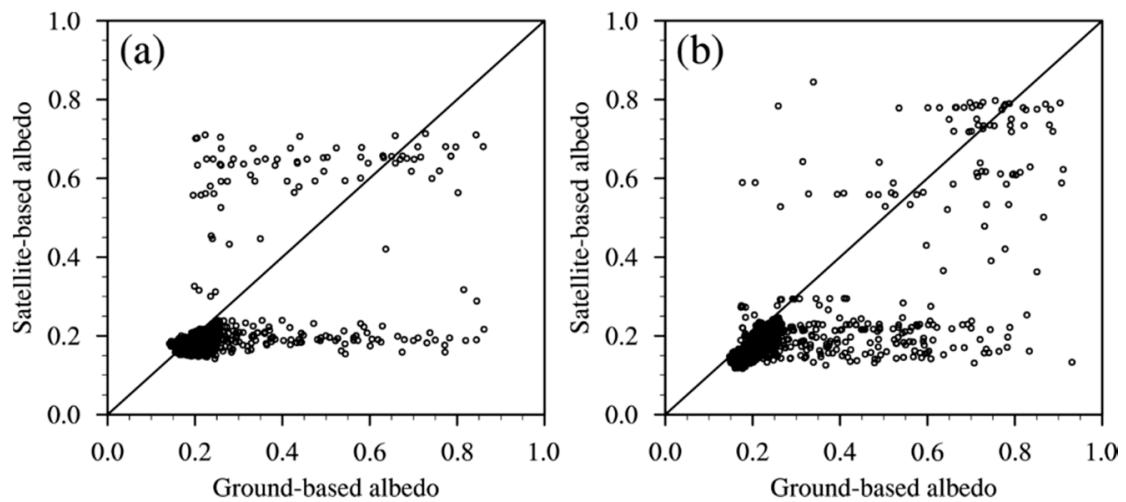

Figure 11. Scatter plots of the blue-sky-albedo of MCD43A3 and daily ground-based observation at (a) Maqu site from January 2009 to June 2017 and (b) Maduo site from January 2011 to June 2017.

From the above results, it can be concluded that GLASS and MCD43B3 albedo products have certain accuracy at the sites of surface cover type represented by alpine meadows on TP, which can basically reflect the annual and seasonal changes of the surface albedo. GLASS and MODIS products use different inversion algorithms, namely, STF and AMBRALS. The final GLASS product is obtained by fusing its initial products and MCD43 products through the STF algorithm. GLASS albedo change is stable when reflecting a long albedo time sequence. The $\mathrm{R}$ with the ground-based albedo of Maduo site reached 0.830 from 2011 to 2016. The accuracy of GLASS product relies on Angular Bin and STF algorithms. The Angular Bin algorithm uses the input data from a single angle, which is suboptimal in capturing the anisotropic reflectance behavior $[15,60]$. STF algorithm effectively reduces the missing data caused by clouds, but it also causes data distortion in the fusion process. Although GLASS captured the slowdown processes of snow albedo at Maduo site from 2 December to 10 December 2016, many processes of rapid changes in albedo are still missing. 
Both MCD43A3 and MCD43B3 albedos use the AMBRALS algorithm to achieve a linear description of the bidirectional reflectance on the basis of BRDF model. In the kernel-driven semiempirical approach, the BRDF is modeled as a weighted sum of a volume scattering function and a surface scattering function (called kernels) and a constant [64]. This combination has proved to be very suitable for describing the bidirectional reflectance anisotropy of the land surface for different plants [65]. However, the AMBRALS algorithm usually requires long-term sequential ground measurements to calculate albedo, resulting in a low temporal resolution, which cannot reflect rapid changes of albedo during rainfall, snowfall, or rapid plant growth. MCD43A3 product have shown some advantages over MCD43B3 in characterizing the albedo changes during the snowfall and rainfall periods, because it uses L2G-lite surface reflectance as input and uses a database with archetypal BRDF parameters to supplement the observational data and performs a lower quality magnitude inversion when high-quality reflectance is insufficient. Also, the database will be continually updated with the latest full inversion retrieval for each pixel. Although the algorithm of MCD43A3 product has been considerably improved, it still missed capturing the slowdown processes of albedo changes resulted by small snowfall processes or the snow aging, and its accuracy is greatly affected by cloud cover.

Remote sensing data matches nonremote sensing data and input into quantitative remote sensing models to obtain the products through inversion. Extremely complex topography, diverse surface types, and severe weather changes have increased the difficulty of obtaining data on the TP. More snowfalls in spring, strong solar radiation, wind-blowing snow, thin snow cover, and fast snowmelt in the study area are also different from other areas. Davidson and Wang [6] have pointed out that snow cover increases not only the albedo of all cover types but also their sensitivities to changes in SZA. The density of ground observation sites on the TP is rarely sufficient to accurately characterize albedo at a regional scale. MCD43A3 product has better quality at high latitudes by using all available observations during the acquisition period, while the MCD43B3 is limited to only four valid observations per day, so that it cannot capture many subtle dynamic changes in albedo.

Accurately characterizing the diurnal variation of surface albedo is very important for monitoring radiative transfers between soil, vegetation, and atmosphere [66]. Most current climate models rely on field measurements to calculate or deduce surface albedo [67]. The absolute accuracy required ranges from 0.02 to 0.05 [68]. But GLASS and MODIS albedo products are still limited by temporal resolution. For example, in the Maqu region, the morning snowfall has melted in the afternoon due to strong solar radiation at noon. Even if the MODIS sensor transits twice a day, it cannot detect the rapid diurnal changes in snow accumulation and melting. At this time, e.g., Chinese geostationary Fengyun meteorological satellite data could be used as a supplement. In addition, GLASS and MODIS albedos have obvious biases in winter due to the effects of snow and cloud cover. For example, none of them reflected the gradual change of the albedo of Maqu in Figure 7a from 12 to 15 January 2015.

Scale gap between ground-based observation and pixel scale is another factor affecting the accuracy of remote sensing albedo product in direct verification. Certainly, more ground-based measurements or upscaling observational technique should be further performed for advanced evaluation. Improving the temporal resolution of remote sensing albedo product and accurately reflecting the rapid change in albedo are still difficult for future inversion. Despite the limited geographic region of the study area, it still provides a basis for the accuracy verification of surface albedo products and also lays a foundation for the direct application of remote sensing albedo products in the land surface model.

\section{Conclusions}

Based on the 8-year ground-based observation of the surface albedo over typical alpine meadows at Maqu and Maduo sites in the eastern TP, the performance of surface albedo products of GLASS and MODIS were assessed to investigate surface albedo changes at daily, 8-day, seasonal timescales, and during different special weather conditions, as well as the main causes of surface albedo product bias were analyzed in detail. The main conclusions are as follows: 
(1) In an 8-day timescale, the ground-based albedos are concentrated in 0.16-0.67 and 0.16-0.76 at Maqu and Maduo sites, respectively. The BSA of GLASS and MCD43B3 are less than the average ground-based observation of Maqu by 0.030 and 0.027. GLASS's BSA albedo coincides well with the ground-based observation in Maduo, with RMSE of 0.092 and R of 0.833 , while that of MCD43B3 had an RMSE of 0.072 and R of 0.752 . But they are underestimated when the albedo is greater than 0.4 . The 8-day albedo of this period happened to be averaged based on the number of snow-covered days.

(2) In seasonal timescale, the ground-based albedos vary with the largest range in winter and the smallest in summer, which are $0.20-0.67$ and $0.17-0.22$ at Maqu site and 0.19-0.74 and $0.17-0.21$, respectively. The BSA of GLASS and MCD43B3 underestimated the ground-based observation of Maqu by 0.015 in summer, while their WSA are slightly overestimated and closer to the ground-based observation. The maximum biases of GLASS and MCD43B3 albedos from Maduo ground-based observation are 0.042 and 0.053 in summer and 0.155 and 0.171 in winter, respectively.

(3) Under special weather conditions, the response of surface albedo to soil moisture is different in semihumid and semiarid areas in summer. For both sites, the blue-sky-albedo of MCD43A3 has better agreement with the ground-based albedo than the GLASS and MCD43B3, as it is more suitable for reflecting the albedo changes in a short period by improving the temporal resolution, and calculates the albedo by weighting multiple observations within 16 days to be closer to the actual surface. However, it still missed capturing the slowdown processes of albedo changes resulted by small snowfall processes or the snow aging due to the cloud cover and inversion algorithms. GLASS and MCD43B3 albedos are frequently small and have the missing or misrepresentation of rapid changes in albedo caused by snowfall and rainfall on the TP.

Author Contributions: Conceptualization, Y.A., G.L., and Y.M.; methodology, Y.A. and X.M.; validation, Y.A., L.Z., and Z.L.; writing—original draft, Y.A.; writing—review and editing, X.M., L.Z., Z.L., S.W., L.S., H.C., and S.L. All authors have read and agreed to the published version of the manuscript.

Funding: This study is under the auspices of the Chinese National Science Foundation Programs 41822501, 91837209, and 41930759, the Second Tibetan Plateau Scientific Expedition and Research Program (STEP), 2019QZKK010202, the Chinese National Science Foundation Programs 41975012, 41775016, and 41675157, and the Outstanding members of Chinese Academy of Youth Innovation and Promotion, Y201874.

Acknowledgments: Acknowledgement for the data support from "National Earth System Science Data Center, National Science \& Technology Infrastructure of China. (http://www.geodata.cn)." We thank the LP DAAC for providing MODIS surface albedo data and also thank the ground-based observations provided by the Zoige Plateau Wetland Ecosystem Research Station.

Conflicts of Interest: The authors declare no conflict of interest.

\section{References}

1. Dickinson, R.E. Land surface processes and climate-surface albedos and energy balance. Adv. Geophys. 1983, 25, 305-353.

2. Baret, F.; Schaaf, C.; Morisette, J.; Privette, J. Report on the second international workshop on albedo product validation. In Michael King, EOS Project Scientist, NASA's Earth Observing System Project Science Office, USA. Earth Obs. 2005, 17, 13-17.

3. Hall, A. The role of surface albedo feedback in climate. J. Clim. 2004, 17, 1550-1568. [CrossRef]

4. Cess, R.D. Biosphere-albedo feedback and climate modeling. J. Atmos. Sci. 1978, 35, 1765-1768. [CrossRef]

5. Barry, R.G.; Chorley, R.J. Atmosphere, Weather and Climate; Routledge: New York, NY, USA, 2009.

6. Davidson, A.; Wang, S.S. The effects of sampling resolution on the surface albedos of dominant land cover types in the North American boreal region. Remote Sens. Environ. 2004, 93, 211-224. [CrossRef]

7. Liang, S.L. Narrowband to broadband conversions of land surface albedo I: Algorithms. Remote Sens. Environ. 2001, 76, 213-238. [CrossRef] 
8. Engelsen, O.; Pinty, B.; Verstraete, M.M.; Martonchik, J.V. Parametric Bidirectional Reflectance Factor Models: Evaluation, Improvements and Applications; Joint Research Centre, Ed.; Technical Report EUR 16426 EN; Office for Official Publications of the European Communities: Ispra, Italy, 1996.

9. Liang, S.L.; Strahler, A.H.; Walthall, C. Retrieval of land surface albedo from satellite observations: A simulation study. J. Appl. Meteorol. 1999, 38, 712-725. [CrossRef]

10. Lucht, W.; Schaaf, C.B.; Strahler, A.H. An algorithm for the retrieval of albedo from space using semiempirical BRDF models. IEEE Trans. Geosci. Remote 2000, 38, 977-998. [CrossRef]

11. Jin, Y.; Gao, F.; Schaaf, C.B.; Li, X.W.; Strahler, A.H.; Bruegge, C.J.; Martonchik, J.V. Improving MODIS surface BRDF/albedo retrieval with MISR multiangle observations. IEEE Trans. Geosci. Remote 2002, 40, 1593-1604.

12. Qu, Y.; Liu, Q.; Liang, S.L.; Wang, L.Z.; Liu, N.F.; Liu, S.H. Direct-estimation algorithm for mapping daily land-surface broadband albedo from MODIS data. IEEE Trans. Geosci. Remote 2014, 52, 907-919. [CrossRef]

13. Diner, D.J.; Martonchik, J.V.; Kahn, R.A.; Pinty, B.; Gobron, N.; Nelson, D.L.; Holben, B.N. Using angular and spectral shape similarity constraints to improve MISR aerosol and surface retrievals over land. Remote Sens. Environ. 2005, 94, 155-171. [CrossRef]

14. Wen, J.G.; Dou, B.C.; You, D.Q.; Yong, T.; Qing, X.; Liu, Q.; Liu, Q.H. Forward a small-timescale BRDF/Albedo by multisensor combined BRDF inversion model. IEEE Trans. Geosci. Remote 2017, 55, 683-697. [CrossRef]

15. Wu, X.D.; Wen, J.G.; Xiao, Q.; You, D.Q.; Dou, B.C.; Lin, X.W.; Hueni, A. Accuracy Assessment on MODIS (V006), GLASS and MuSyQ Land-Surface Albedo Products: A Case Study in the Heihe River Basin, China. Remote Sens. 2018, 10, 2045. [CrossRef]

16. Lyapustin, A.; Wang, Y.; Kahn, R.; Xiong, J.; Ignatov, A.; Wolfe, R.; Wu, A.; Holben, B.; Bruegge, C. Analysis of MODIS-MISR calibration differences using surface albedo around AERONET sites and cloud reflectance. Remote Sens. Environ. 2007, 107, 12-21. [CrossRef]

17. Taberner, M.; Pinty, B.; Govaerts, Y.; Liang, S.; Verstraete, M.M.; Gobron, N.; Widlowski, J.L. Comparison of MISR and MODIS land surface albedos: Methodology. J. Geophys. Res. Atmos. 2010, 115. [CrossRef]

18. Lucht, W.; Hyman, A.H.; Strahler, A.H.; Barnsley, M.J.; Hobson, P.; Muller, J.P. A comparison of satellite-derived spectral albedos to ground-based broadband albedo measurements modeled to satellite spatial scale for a semidesert landscape. Remote Sens. Environ. 2000, 74, 85-98. [CrossRef]

19. Liang, S.L.; Fang, H.L.; Chen, M.Z.; Shuey, C.J.; Walthall, C.; Daughtry, C.; Morisette, J.; Schaaf, C.; Strahler, A. Validating MODIS land surface reflectance and albedo products: Methods and preliminary results. Remote Sens. Environ. 2002, 83, 149-162. [CrossRef]

20. Salomon, J.G.; Schaaf, C.B.; Strahler, A.H.; Gao, F.; Jin, Y. Validation of the MODIS bidirectional reflectance distribution function and albedo retrievals using combined observations from the Aqua and Terra platforms. IEEE Trans. Geosci. Remote 2006, 44, 1555-1565. [CrossRef]

21. Román, M.O.; Schaaf, C.B.; Woodcock, C.E.; Strahler, A.H.; Yang, X.Y.; Braswell, R.H.; Curtis, P.S.; Davis, K.J.; Dragoni, D.; Goulden, M.L.; et al. The MODIS (Collection V005) BRDF/albedo product: Assessment of spatial representativeness over forested landscapes. Remote Sens. Environ. 2009, 113, 2476-2498. [CrossRef]

22. Stroeve, J.; Box, J.E.; Gao, F.; Liang, S.; Nolin, A.; Schaaf, C. Accuracy assessment of the MODIS 16-day albedo product for snow: Comparisons with Greenland in situ measurements. Remote Sens. Environ. 2005, 94, 46-60. [CrossRef]

23. Williamson, S.N.; Copland, L.; Hik, D.S. The accuracy of satellite-derived albedo for northern alpine and glaciated land covers. Polar Sci. 2016, 10, 262-269. [CrossRef]

24. Moustafa, S.E.; Rennermalm, A.K.; Román, M.O.; Wang, Z.; Schaaf, C.B.; Smith, L.C.; Koenig, L.C.; Erb, A. Evaluation of satellite remote sensing albedo retrievals over the ablation area of the southwestern Greenland ice sheet. Remote Sens. Environ. 2017, 198, 115-125. [CrossRef]

25. Pinty, B.; Taberner, M.; Haemmerle, V.R.; Paradise, S.R.; Vermote, E.; Verstraete, M.M.; Gobron, N.; Widlowski, J.L. Global-scale comparison of MISR and MODIS land surface albedos. J. Clim. 2011, 24, 732-749. [CrossRef]

26. Liu, Y.; Wang, Z.S.; Sun, Q.S.; Erb, A.M.; Li, Z.; Schaaf, C.B.; Zhang, X.Y.; Román, M.O.; Scotte, R.L.; Zhang, Q.; et al. Evaluation of the VIIRS BRDF, Albedo and NBAR products suite and an assessment of continuity with the long term MODIS record. Remote Sens. Environ. 2017, 201, 256-274. [CrossRef]

27. He, T.; Liang, S.L.; Wang, D.D.; Cao, Y.F.; Gao, F.; Yu, Y.Y.; Feng, M. Evaluating land surface albedo estimation from Landsat MSS, TM, ETM+, and OLI data based on the unified direct estimation approach. Remote Sens. Environ. 2018, 204, 181-196. [CrossRef] 
28. Duan, A.M.; Wu, G.X.; Liu, Y.M.; Ma, Y.M.; Zhao, P. Weather and climate effects of the Tibetan Plateau. Adv. Atmos. Sci. 2012, 29, 978-992. [CrossRef]

29. Ma, Y.M.; Hu, Z.Y.; Tian, L.; Zhang, F.; Duan, A.; Yang, K.; Zhang, Y.L.; Yang, Y.P. Study progresses of the Tibet Plateau climate system change and mechanism of its impact on East Asia. Adv. Earth Sci. 2014, 29, 207-215.

30. Wu, G.X.; Zhang, Y.S. Tibetan Plateau forcing and the timing of the monsoon onset over South Asia and the South China Sea. Mon. Weather Rev. 1998, 126, 913-927. [CrossRef]

31. Li, W.K.; Guo, W.D.; Qiu, B.; Xue, Y.K.; Hsu, P.C.; Wei, J.F. Influence of Tibetan Plateau snow cover on East Asian atmospheric circulation at medium-range time scales. Nat. Commun. 2018, 9, 4243. [CrossRef]

32. An, Y.Y.; Meng, X.H.; Zhao, L.; Li, Z.G.; Lv, S.H.; Ma, Y.T. Evaluation the applicability of albedo products of GLASS, MODIS and GlobAlbedo under the alpine meadow over the Qinghai-Tibetan Plateau. Plateau Meteor. 2019, 38, 88-100.

33. Wang, K.C.; Liu, J.M.; Zhou, X.J.; Sparrow, M.; Ma, M.; Sun, Z.A.; Jiang, W.H. Validation of the MODIS global land surface albedo product using ground measurements in a semidesert region on the Tibetan Plateau. J. Geophys. Res. Atmos. 2004, 109, 107. [CrossRef]

34. Qin, D.H.; Liu, S.Y.; Li, P.J. Snow cover distribution, variability, and response to climate change in western China. J. Clim. 2006, 19, 1820-1833.

35. Wang, W.L.; Yang, K.; Zhao, L.; Zheng, Z.Y.; Lu, H.; Mamtimin, A.; Ding, B.H.; Li, X.; Zhao, L.; Li, H.Y.; et al. Characterizing surface albedo of shallow fresh snow and its importance for snow ablation on the interior of the Tibetan Plateau. J. Hydrometeorol. 2020, 21, 815-827. [CrossRef]

36. Pu, Z.X.; Xu, L.; Salomonson, V.V. Modis/Terra observed seasonal variations of snow cover over the Tibetan Plateau. Geophys. Res. Lett. 2007, 34, 137-161. [CrossRef]

37. Liang, S.L.; Zhang, X.T.; Xiao, Z.Q.; Cheng, J.; Liu, Q.; Zhao, X. Global Land Surface Satellite (GLASS) Products:Algorithms, Validation and Analysis, Springerbriefs in Earth Sciences; Springer: New York, NY, USA, 2013.

38. Liang, S.L.; Zhao, X.; Liu, S.H.; Yuan, W.P.; Cheng, X.; Xiao, Z.Q.; Zhang, X.T.; Liu, Q.; Cheng, J.; Tang, H.R.; et al. A long-term Global Land Surface Satellite (GLASS) data-set for environmental studies. Int. J. Digit. Earth 2013, 6 (Suppl. S1), 5-33. [CrossRef]

39. Running, S.W.; Justice, C.O.; Salomonson, V.; Hall, D.; Barker, J.; Kaufmann, Y.J.; Strahler, A.H.; Huete, A.R.; Muller, J.P.; Vanderbilt, V.; et al. Terrestrial remote sensing science and algorithms planned for EOS/MODIS. Int. J. Remote Sens. 1994, 15, 3587-3620. [CrossRef]

40. Justice, C.O.; Townshend, J.R.G.; Vermote, E.F.; Masuoka, E.; Wolfe, R.E.; Saleous, N.; Roy, D.P.; Morisette, J.T. An overview of MODIS Land data processing and product status. Remote Sens. Environ. 2002, 83, 3-15. [CrossRef]

41. Nightingale, J.; Nickeson, J.; Justice, C.; Baret, F.; Garrigues, S.; Wolfe, R.; Masuoka, E. Global Validation of EOS Land Products, Lessons Learned and Future Challenges: A MODIS Case Study. In Proceedings of the 33rd International Symposium on Remote Sensing of Environment, Sustaining the Millennium Development Goals, Stresa, Italy, 4-8 May 2008.

42. Justice, C.O.; Vermote, E.; Townshend, J.R.; Defries, R.; Roy, D.P.; Hall, D.K.; Salomonson, V.V.; Privette, J.L.; Riggs, G.; Strahler, A.; et al. The Moderate Resolution Imaging Spectroradiometer (MODIS): Land remote sensing for global change research. IEEE Trans. Geosci. Remote 1998, 36, 1228-1249. [CrossRef]

43. Wang, S.Y.; Zhang, Y.; Lü, S.H.; Su, P.X.; Shang, L.Y.; Li, Z.G. Biophysical regulation of carbon fluxes over an alpine meadow ecosystem in the eastern Tibetan Plateau. Int. J. Biometeorol. 2016, 60, 801-812. [CrossRef]

44. Wang, S.Y.; Zhang, Y.; Lü, S.H.; Shang, L.Y.; Su, Y.Q.; Zhu, H.H. Radiation balance and the response of albedo to environmental factors above two alpine ecosystems in the eastern Tibetan Plateau. Sci. Cold Arid Reg. 2017, 9, 142-150.

45. Kipp \& Zonen. Instruction Manual for CNR1 Net Radiometer; Campbell Scientific, Inc.: Logan, UT, USA, 2002.

46. Kipp \& Zonen. Instruction Manual for CNR4 Net Radiometer; Campbell Scientific, Inc.: Logan, UT, USA, 2014.

47. Chen, A.J.; Hu, S.S.; Bian, L.G.; Liu, Y.J. An assessment on the accuracy of the GLASS albedo products over the Tibetan Plateau. Acta Meteorol. Sin. 2015, 73, 1114-1120.

48. Stokes, G.M.; Schwartz, S.E. The atmospheric radiation measurement (ARM) program: Programmatic background and design of the cloud and radiation test bed. Bull. Am. Meteorol. Soc. 1994, 75, 1201-1221. [CrossRef] 
49. Román, M.O.; Schaaf, C.B.; Lewis, P.; Gao, F.; Anderson, G.P.; Privette, J.L.; Strahler, A.H.; Woodcock, C.E.; Barnsley, M. Assessing the coupling between surface albedo derived from MODIS and the fraction of diffuse skylight over spatially-characterized landscapes. Remote Sens. Environ. 2010, 114, 738-760. [CrossRef]

50. Shi, Q.Q.; Liang, S.L. Characterizing the surface radiation budget over the Tibetan Plateau with ground-measured, reanalysis, and remote sensing data sets. Part 2: Spatiotemporal analysis. J. Geophys. Res. Atmos. 2013, 118, 8921-8934. [CrossRef]

51. Liu, N.F.; Liu, Q.; Wang, L.Z.; Liang, S.L.; Wen, J.G.; Qu, Y.; Liu, S.H. A statistics-based temporal filter algorithm to map spatiotemporally continuous shortwave albedo from MODIS data. Hydrol. Earth Syst. Sci. 2013, 17, 2121-2129. [CrossRef]

52. Campbell, G.S.; Norman, J.M. An Introduction to Environmental Biophysics; Springer: New York, MY, USA, 1998.

53. Wei, W.S.; Qin, D.H.; Liu, M.Z. Properties and structure of the seasonal snow cover in the northwest regions of China. Arid Land Geogr. 2001, 24, 310-313.

54. Wiscombe, W.J.; Warren, S.G. A model for the spectral albedo of snow. I Pure Snow. J. Atmos. Sci. 1980, 37, 2712-2733. [CrossRef]

55. Warren, S.G. Optical properties of snow. Rev. Geophys. Space Phys. 1982, 20, 67-89. [CrossRef]

56. Fujinami, H.; Yasunari, T. The seasonal and intraseasonal variability of diurnal cloud activity over the Tibetan Plateau. J. Meteorol. Soc. Jpn. 2001, 79, 1207-1227. [CrossRef]

57. Wang, K.C.; Liang, S.L.; Schaaf, C.L.; Strahler, A.H. Evaluation of Moderate Resolution Imaging Spectroradiometer land surface visible and shortwave albedo products at FLUXNET sites. J. Geophys. Res. Atmos. 2010, 115. [CrossRef]

58. Schaaf, C.B.; Wang, Z.; Strahler, A.H. Commentary on Wang and Zender-MODIS snow albedo bias at high solar zenith angles relative to theory and to in situ observations in Greenland. Remote Sens. Environ. 2011, 115, 1296-1300. [CrossRef]

59. Liang, S.L. A direct algorithm for estimating land surface broadband albedos from MODIS imagery. IEEE Trans. Geosci. Remote 2003, 41, 136-145. [CrossRef]

60. Qi, W.D.; Liu, Q.; Hong, Y.T. Comparison analysis based on different inverse algorithms of surface albedo products. J. Remote Sens. 2014, 18, 559-572.

61. Hall, D.K.; Riggs, G.A.; Salomonson, V.V.; DiGirolamo, N.E.; Bayr, K.J. MODIS snow-cover products. Remote Sens. Environ. 2002, 83, 181-194. [CrossRef]

62. Klein, A.G.; Barnett, A.C. Validation of daily MODIS snow cover maps of the Upper Rio Grande River Basin for the 2000-2001 snow year. Remote Sens. Environ. 2003, 86, 162-176. [CrossRef]

63. Liu, W.D.; Baret, F.; Gu, X.F.; Tong, Q.X.; Zheng, L.F.; Zhang, B. Relating soil surface moisture to reflectance. Remote Sens. Environ. 2002, 81, 238-246.

64. Hu, B.; Lucht, W.; Li, X.; Strahler, A. Validation of kernel-driven semiempirical models for the surface bidirectional reflectance distribution function of land surfaces. Remote Sens. Environ. 1997, 62, 201-214. [CrossRef]

65. Privette, J.L.; Eck, T.F.; Deering, D.W. Estimating spectral albedo and nadir reflectance through inversion of simple BRDF models with AVHRR/MODIS-like data. J. Geophys. Res. Atmos. 1997, 102, 29529-29542. [CrossRef]

66. Sellers, P.; Hall, F.; Margolis, H.; Kelly, B.; Baldocchi, D.; den Hartog, G.; Cihlar, J.; Ryan, M.G.; Goodison, B.; Crill, P.; et al. The boreal ecosystem-atmosphere study (BOREAS): An overview and early results from the 1994 field year. Bull. Am. Meteorol. Soc. 1995, 76, 1549-1577. [CrossRef]

67. Henderson-Sellers, A.; Wilson, M.F. Surface albedo data for climate modeling. Rev. Geophys. 1983, 21, 1743-1778. [CrossRef]

68. Jacob, F.; Olioso, A. Derivation of diurnal courses of albedo and reflected solar irradiance from airborne polder data acquired near solar noon. J. Geophys. Res. 2005, 110, 104. [CrossRef]

(C) 2020 by the authors. Licensee MDPI, Basel, Switzerland. This article is an open access article distributed under the terms and conditions of the Creative Commons Attribution (CC BY) license (http://creativecommons.org/licenses/by/4.0/). 